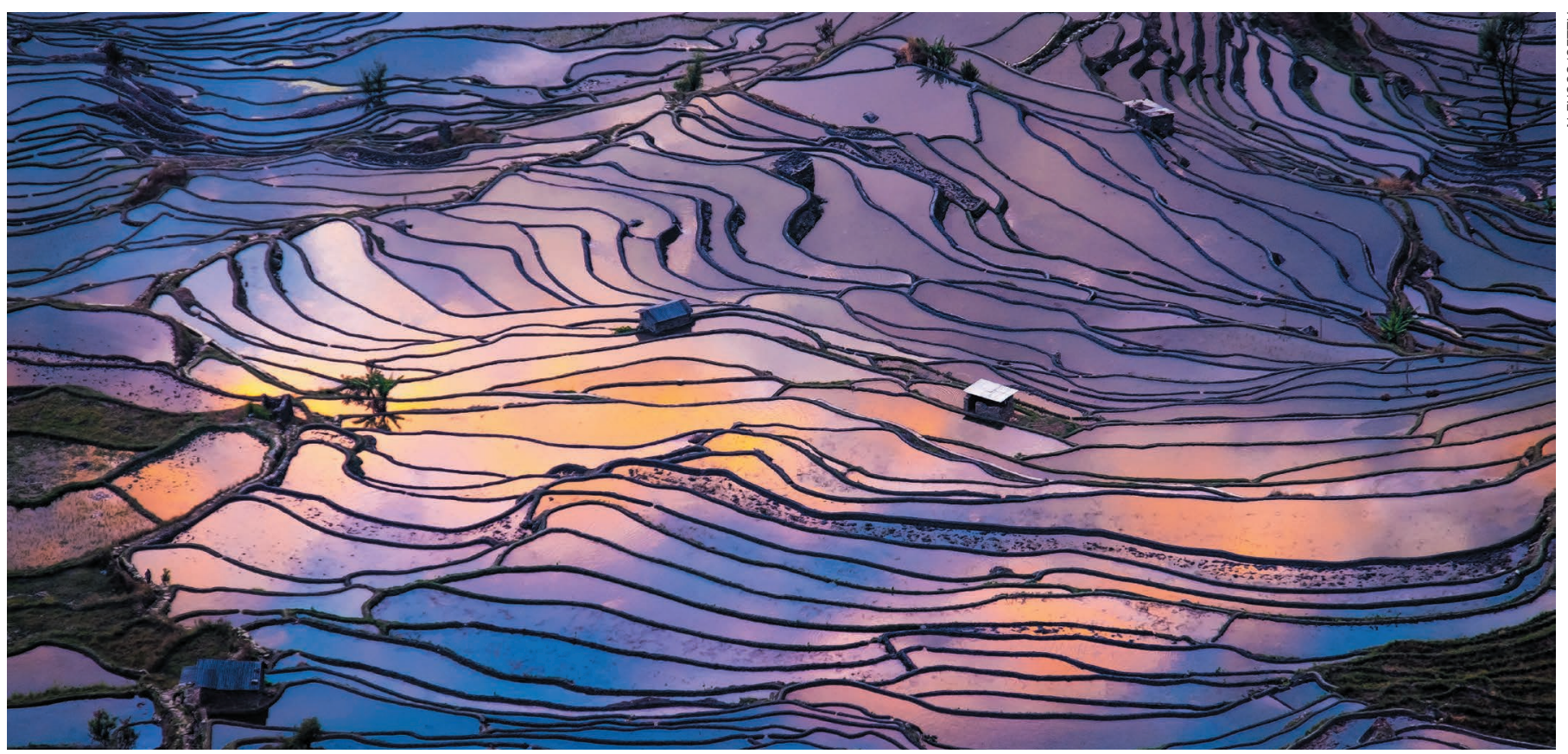

Terraced rice fields in China: agriculture is one of the many human influences that has shaped Earth's history.

\title{
Involve social scientists in defining the Anthropocene
}

\section{The causes of Earth's transition are human and social, write Erle Ellis and colleagues, so scholars from those disciplines must be included in its formalization.}

$\mathrm{T}$ hree dozen academics are planning to rewrite Earth's history. The Anthropocene Working Group of the International Commission on Stratigraphy (of which one of us, E.E., is a member) announced in August that over the next three years it will divide Earth's story into two parts: one in which humans are a geological superpower - an epoch called the Anthropocene - and the other encompassing all that came before our species had a major influence on Earth's functioning ${ }^{1}$.

Where to put the transition is being debated. Discussions have narrowed to defining one or more 'golden spikes': sharp global signatures in the rock record derived from the introduction of mid-twentieth century technologies, from radionuclides to plastics. Such markers will be put forward as the basis for ratifying the epoch by the executive committee of the International Union of Geological Sciences.

We agree that human influences on the planet should be recognized - but the formalization of the Anthropocene should not be rushed. And we question the privileging of 1950s-era markers. This ignores millennia of previous human influences, from our use of fire to the emergence of agriculture ${ }^{2-6}$. Moreover, these markers misrepresent the continuous nature of human changes to our planet. They instil a Eurocentric, elite and technocratic narrative of human engagement with our environment that is out of sync with contemporary thought in the social sciences and the humanities ${ }^{3,7-9}$.

Decades of rigorous scientific research into the history, causes and consequences of the long-term reshaping of Earth systems by humans is being ignored in the group's discussions. How can a human-centred geological period be defined without characterizing the development of societies, urbanization, colonization, trading networks, ecosystem engineering and energy transitions from biomass to fossil fuels?

We call for the Anthropocene formalization process to be rebuilt on a rigorous, transparent, open and sustainable foundation in which the human sciences have a major role.

\section{DEEPER AND THICKER}

The Anthropocene was not made in a day, nor was it created uniformly: the material records of human alterations of Earth are thick, deep and heterogeneous. They highlight huge social, cultural and technological differences across time and space ${ }^{7,8}$.

Human activities over the past 10,000 years have caused extinctions and global changes in the distribution of wild and domesticated plants, animals and microflora. Land clearance has altered patterns of erosion and released greenhouse gases into the atmosphere. Humans have created materials such as ceramics, brick and concrete as well as pollutants. Vast networks of canals, reservoirs and irrigation - such as those associated with the Angkor Wat temple complex in Cambodia - have shaped lands and ecologies $^{2-4,6,10}$.

Agriculture, which emerged in more than a dozen places at different times starting more than 10,000 years ago, has left a vast and indelible record across most of Earth's continents. Although no one yet knows the fate of plastics, the fossil record of agriculture is well documented in ancient pollen, seeds, parasites, bones, deposits of charcoal and soils. Giant irrigation networks can be traced from the air or space.

Earth sciences long ago moved away from 


\section{THE DEEP ROOTS OF THE ANTHROPOCENE}

Human societies began altering Earth long ago. Human social and cultural capacities to alter its environmental processes have

accumulated, scaled up and reinforced each other in complex and historically contingent ways. Defining an Anthropocene epoch should

involve examining these transformative social-environmental changes, rather than solely focusing on globally instantaneous environmenta

transitions. 'Golden spikes' mark stratigraphic boundaries of geological time periods; '?' highlight recent boundary proposals.

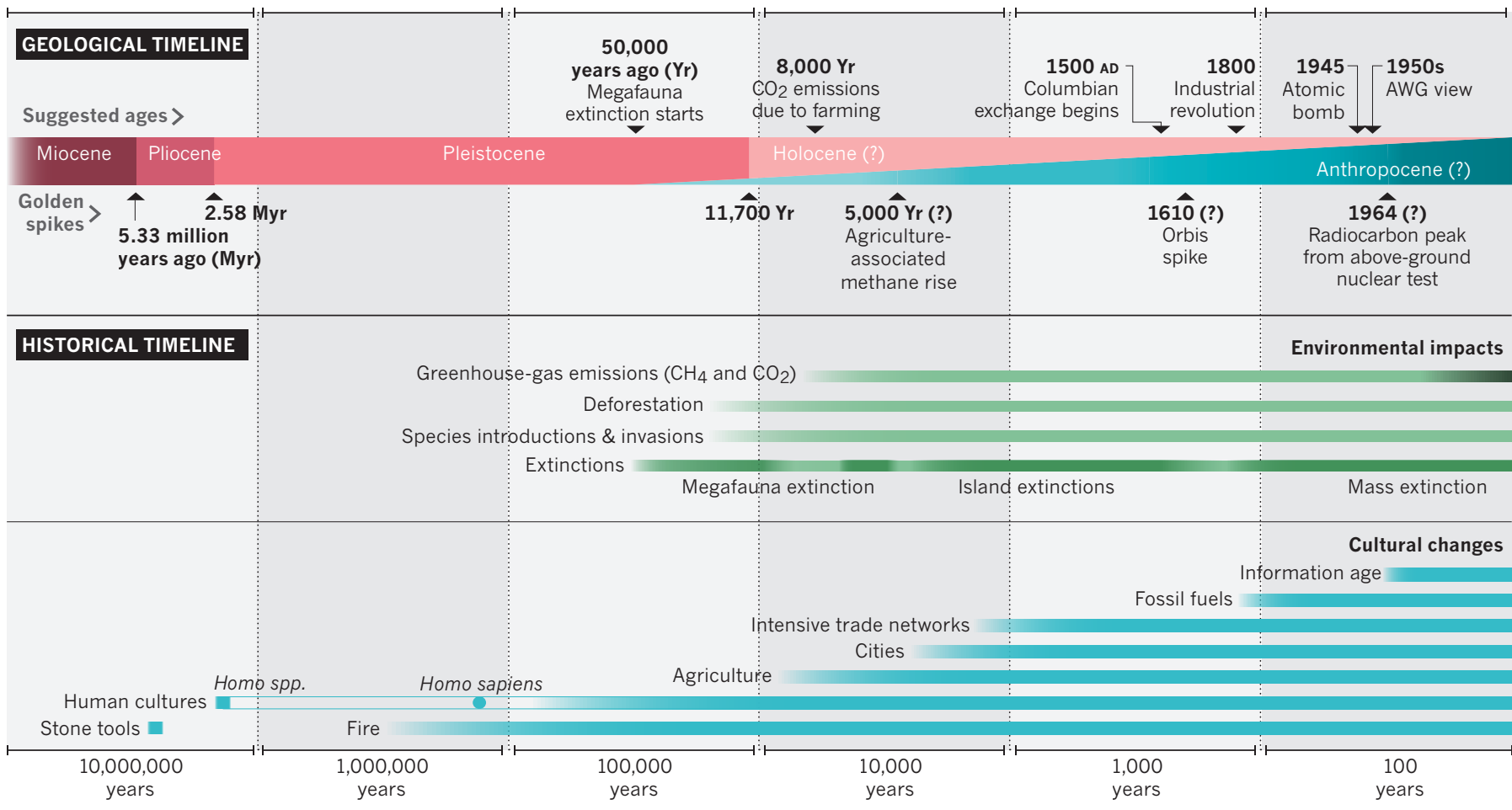

AWG, Anthropocene Working Group

almost exclusively on geological deposits that pinpoint one event simultaneously around the world. The reason seems clear to us. Although the group does include members outside the natural sciences (such as a journalist, a lawyer and historians of science) only 3 of the 37 members are social scientists who study long-term social change (two archaeologists and one historian).

and industrialization are gradual processe that emerged at different times across Earth (see 'The deep roots of the Anthropocene').

Understanding 'human systems' requires engaging a vast body of scholarship based on a diverse array of records (including archaeological, historical and palaeoecological) and perspectives (from political ecology, political economy, historical ecology, cultural evolution and environmental ethics, for instance). Understanding changes in global climate, for example, requires knowing how social and cultural processes drive the clearance of agricultural land and exchanges of atmospheric greenhouse gases, moisture and energy. These processes range from the practices of agricultural land management to demographic shifts, land grabbing and societal conflict.

The Anthropocene Working Group has thrown in a few deeper anthropogenic signals, such as pollution caused by the first production of metals. But these have hardly been considered because the records vary in extent, timing and geographical availability. Instead, the group has focused

\section{MORE INCLUSIVE}

The formalization of the Anthropocene must be more transparent and have wider input and assessment. The criteria for assessing the sciences of the new epoch need to be published and peer reviewed, rather than agreed in private meetings. An open online platform could host the full range of proposals and research papers as well as feedback and discussion. The Intergovernmental Panel on Climate Change and the UK Royal Society and US National Science Foundation Assessment Reports serve as models.

A dedicated scientific institution, perhaps called the International Anthropocene Commission, should coordinate this. It could be set up and funded under the auspices of the International Geological Congress, Future Earth (a ten-year international research initiative on global change) and the United Nations. Half of its members should be drawn from anthropology, archaeology, history, sociology, geography, palaeoecology, economics and philosophy. It should have a formal procedure for inclusion.

Defining a human-centred epoch will take time. It should be treated by scholars from all disciplines with the seriousness it deserves.

Erle Ellis is in the Department of Geography \& Environmental Systems, University of Maryland, Baltimore County, Baltimore, Maryland, USA. Mark Maslin is in the Department of Geography, University College London, UK. Nicole Boivin is at the Max Planck Institute for the Science of Human History, Jena, Germany. Andrew Bauer is in the Department of Anthropology, Stanford University, Stanford, California, USA.

e-mail:ece@umbc.edu

1. Waters, C. N. et al. Science 351, aad2622 (2016)

2. Ellis, E. C. Ecol. Monogr. 85, 287-331 (2015).

3. Boivin, N. L. et al. Proc. Natl Acad. Sci. USA 113, 6388-6396 (2016)

4. Ruddiman, W. F., Ellis, E. C., Kaplan, J. O. \& Fuller, D. Q. Science 348, 38-39 (2015).

5. Lewis, S. L. \& Maslin, M. A. Nature 519, 171-180 (2015).

6. Smith, B. D. \& Zeder, M. A. Anthropocene 4, 8-13 (2013).

7. Malm, A. \& Hornborg, A. Anthropocene Rev. 1, 62-69 (2014).

8. Bauer, A. M. \& Bhan, M. South Atl. Q. 115, 61-87 (2016)

9. Barry, A. \& Maslin, M. Geo Geog. Environ. 3, e00022 (2016).

10.Edgeworth, M. Geol. Soc. Lond. Spec. Publ. 395, 91-108 (2014). 


\section{CORRECTION}

The Comment 'Involve social scientists in defining the Anthropocene' (E. Ellis et al. Nature 540, 192-193; 2016) incorrectly stated that proposals for defining this epoch will be put forward for ratification by the International Geological Congress. In fact, they will be put to the executive committee of the International Union of Geological Sciences. 